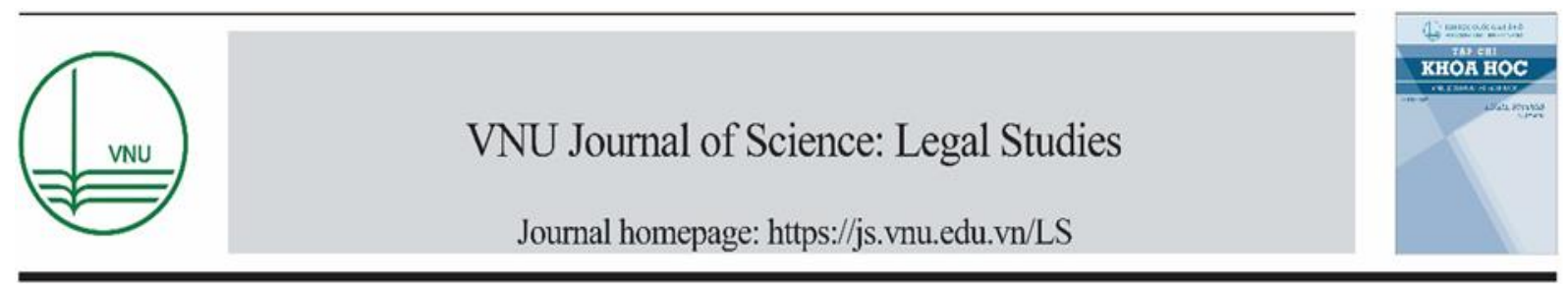

Original Article

\title{
Conflict Between Protection of Industrial Property Rights for Trademarks and Domain Names Under Vietnamese Law
}

\author{
Diep Thi Thanh Xuan* \\ Intellectual Property Office of Vietnam, Nguyen Trai, Thanh Xuan, Hanoi, Vietnam \\ Received 17 April 2021 \\ Revised 25 May 2021; Accepted 26 June 2021
}

\begin{abstract}
Addressing the conflict between protection of industrial property rights for trademarks and domain names from a conflict of rights perspective, this paper focuses on clarifying the nature and causes of this conflict; identifying forms of conflict arising in the protection of industrial property rights for trademarks and the process of registration and use of domain names in business activities of related entities, then this paper will clarify methods for conflict resolution. Based on such theoretical grounds, this paper will analyze and evaluate the current law of Vietnam on resolving conflict between the protection of industrial property rights for trademarks and domain names, identify existing limitations and inadequacies in the law and provide solutions to these problems.
\end{abstract}

Keywords: Trademark, domain name, conflict, intellectual property.

\section{Introduction}

Today, the strong development of the internet and e-commerce not only offers many benefits but also poses many challenges. One of the areas vulnerable to infringement due to the expansion of Internet use is industrial property rights, including trademarks. Many dispute raised from the infringement of industrial property rights for trademarks and domain names have not yet been resolved, this issue

\footnotetext{
${ }^{*}$ Corresponding author.

E-mail address: diepthanhxuan248@yahoo.com https://doi.org/10.25073/2588-1167/vnuls.4366
}

prompts legislators and policy makers to find solutions for the purpose of effectively protecting intellectual property rights in the digital environment, protecting consumers from being confused and deceived, as well as promoting internet freedom and facilitating the development of e-commerce.

Most current research, at different scales, mainly focus on the conflict between trademarks and domain names and haven't delved into the conflict between protection of industrial property rights for trademarks and domain names. The main reason is due to the approach taken, as there are very few researches that apply the conflict-of-rights 
approach. These researches usually aim to clarify some theoretical issues such as: the concepts of trademark and domain name, the mechanism of establishing rights, the scope of trademark protection and the validity of domain name registration. There is no research which study in-depth and systematically legal issues related to the conflict between protection of industrial property rights for trademarks and domain names such as the nature and causes of conflicts, forms of conflict, legal solutions for conflict resolution. Therefore, it is of absolute necessity to comprehensively study both the theory and practice, identify the nature and causes of the conflict, the forms of conflict and thereby find legal solutions for conflict resolution.

\section{The Nature and Causes of Conflict Between Protection of Industrial Property Rights for Trademarks and Domain Names.}

Currently, there are various points of view on the nature of the conflict between the protection of industrial property rights (IPR) for trademarks and domain names. According to the author, the nature of the conflict between protection of IPR for trademarks and domain names is the conflict between the owner of the protected trademark and the domain name registrant and user. Conflicts of rights are inevitable when the law must simultaneously meet objective of policies that are sometimes contradictory, and harmonize the interests of diverse groups of actors in society. Regarding the issue on the confict mentioned within the scope of this paper, there are two fundamental goals must be simultaneously achieved by law. The first is to ensure fair competition in the market, to protect consumers, and the investment results for trademark owners. The second is to ensure internet freedom, business freedom, especially business freedom in the ecommerce environment, including the freedom of speech. Thus, this is a conflict between two groups of interests: those of the trademark owner and those of the entity registering and using a domain name.

A conflict may arise when: (1) the right of $\mathrm{A}$ is prohibited by $\mathrm{B},(2)$ the obligation of $\mathrm{A}$ and the obligation of $\mathrm{B}$ cannot be performed together, or (3) when an actor has to perform two obligations which cannot be performed together [1]. For trademarks, the exercise of "exclusive right" to prevent acts of unfair competition from other actors may lead to trademark owners taking advantage of their rights to manipulate competitive relations and limit the rights of other actors. On the other hand, the exercise of internet freedom and the freedom of information of domain name registrants may also affect the entitlement of rights of trademark owners. Moreover, once the law must simultaneously meet two objectives which are difficult to be achieved together (protecting the investment results of the trademark owner, protecting consumers, and ensuring internet freedom, business freedom in the digital environment), conflicts are bound to happen. Thus, the conflict between the protection of IPR for trademarks and domain names is the conflict and overlap of rights that occur throughout the whole process from establishing rights to exploiting and protecting rights.

This conflict arises from the emergence and explosion of the internet. The emergence and strong development of the internet led to the existance of a new type of object, the domain name. Domain names play an extremely important role in the era of e-commerce, but it can become a barrier to commerce when being registered and used with malicious intent to infringe the rights of the third party [2]. Initially, a domain name was simply an IP address to identify a website, under the form of a series of numbers, but eventually for convenience, it was converted into words to be easier to read and remember. The development of the internet and e-commerce has gradually shifted the function of domain names from identifying internet addresses to indicating the source as well as for distinguishing products/services - the traditional function of 
trademarks. The proximity of domain names to the function of trademarks is the main cause of conflict. On the other hand, when there is a shift of function as such, it changes the nature of domain names from not being considered as an asset to being considered as a valuable asset recognized in the precedents of developed countries and proven in market practice.

The conflict between the protection of IPR for trademarks and domain names also comes from their nature. The territorial and national nature of the protection of IPR for trademarks and the global and international nature of domain names, the exclusive but limited nature of IPR regarding trademarks and the unique nature of domain names as it is allocated on the principle of "first come, first serve" have led to conflicts and overlap between the protection on them. Moreover, conflict also comes from the independence, even isolation and lack of coordination between the two systems for trademark and domain name registration.

The conflict between IPR protection for trademarks and domain names stems from their similarities and differences. The similarity manifests itself first in the form of expression. Both trademarks and domain names are strings of letters. In terms of function, the initial functions of trademarks and domain names are different, trademarks have the function of distinguishing goods and services of different business entities, while the original function of domain names is to identify the internet address. However, with the development of the internet and e-commerce, today both trademarks and domain names have the function of a commercial indication since both trademarks and domain names contain information and data that are distinctive, directive for the selection of goods, services, and business entities; contain certain indications related to the goods, services, or business entities using such indications and are all distinctive signs [3]. In addition, both aim at personalizing the entity owning the object or products that represent the object, influencing consumers' perception of products and services of certain actors [4].
What make domain names to be different from trademarks is the concept of "confusing similarity" when it comes to domain names. There can be two similar domain names such as www.abcd.com and www.ab-cd.com. Differently, a trademark filed for registration will be refused if it is confusingly similar to a protected trademark of another actor which was filed on an earlier date or on a priority date. For example, a beverage company cannot register the trademark Koka Kola, because it resembles the well-known trademark of the Coca-Cola line. Furthermore, unlike domain names, trademark registration is subject to a product/service classification system, which means that overlapping of trademarks are allowed if their products and services are different. While domain names are unique worldwide, a domain name can only be owned by one entity, regardless of the goods and services offered.

\section{Identify Conflicts Between the Protection of Industrial Property Rights for Trademarks and Domain Names and Methods of Resolution}

Based on the conflict of rights theory, this paper will identify conflicts between the protection of IPR for trademarks and domain names; provide general principles of conflict resolution, and from these general principles, study specific methods of conflict resolution. The general principle used by the author is the one of determining the priority hierarchy of interests to be protected and of balancing and harmonizing the interests of involved parties. These principles are closely interactive to each other, and ultimately all lead to a common value, which is the principle of fairness. More specifically, in the field of intellectual property, inspired by the theory of property law, there are two principles to ensure fairness that are often applied to resolve conflicts and overlapping in the protection of objects of intellectual property, those are the principle of "first in 
time, first in right", and the principle of protecting the party in good faith.

\subsection{Conflicts Between Protection of Industrial Property Rights for Trademarks and Domain Names in Establishing Rights and Methods of Conflict Resolution}

3.1.1. Registering a Domain Name Identical With a Trademark (Cybersquatting)

Trademark is extremely valuable to businesses, as they indicate the origin of goods and services and distinguish goods and services of different business entities. By using trademark, a business can build its reputation, attract customers, and secure a certain position in the market. Trademarks are also a powerful tool used in market competition and a tool to protect consumers from being deceived. Therefore, for the common interest of trademark owners and society as a whole, it is necessary to prevent actors from illegally exploiting the trademarks belonging to other actors.

Trademark infringement arises out of any act that may give rise to the possibility of confusion. The first manifestation of the conflict between the protection of IPR for trademarks and domain names in the stage of establishing rights occurs when an entity uses another's protected trademark to register for a domain name. Clearly in this case, the domain name registrant has absolutely no legitimate rights and interests to that trademark but took the trademark to register as a domain name before the trademark owner carries out the registration, in order to sell the domain name to the trademark owner at a high price or to obstruct the trademark owner's right to register.

The main cause of this form of conflict comes from the principle of "first come, first serve" of domain name registration. This means that the agency for domain name registration does not conduct examinations to assess whether the registration of a domain name by one actor may cause confusion with another's trademark. Therefore, some actors take benefits from the application of the principle of domain name allocation and latter, and then refused, registration of true owner of the mentioned trademark.

3.1.2. Registering a Domain Name Confusingly Similar to a Trademark (Typosquatting)

This is a case where a domain name registrant intentionally takes someone else's protected trademark (but may add or subtract one or more characters) to register a domain name. This form is also known as URL hijacking or domain mimicry to deceive, "lead" consumers to another website. In fact, this form of infringement often occurs with well-known trademarks. Domain name registrants take benefits from the prestige and reputation of these trademarks by "misleading" consumers. According to data from Microsoft, this company has filed more than 300 complaints about false registrations and "confusingly similar" domain names.

It can be seen that, in this case, the conflict and overlapp between the protection of IPR for trademarks and domain names only manifests as a dispute when: i) There is a domain name that is similar to the point of confusion with a protected trademark of another actor and ii) the registrant of the domain name has no legal rights or interests related to the domain name and iii) the registrant of the domain name knows the existence of such trademark but still proceeds with the registration.

3.1.3. Retrieving the Misappropriated Domain Name (Reverse Domain Name Hijacking -RDNH)

"Retrieving the misappropriated domain name" or "reverse domain name hijacking" (RDNH) is when the trademark owner (who has not registered the domain name) has taken advantage of the loopholes in the law, with bad faith methods to get the domain name back from the previous registrant. Clearly in this case, the domain name registrant had registered before the time the trademark was protected, but in fact the domain name registrant has not yet able to protect their domain name from RDNH.

The method of resolving conflicts between the protection of IPR for trademarks and domain names in the stage of establishing rights: It can be seen that the conflicts 
identified above are comprehensive in two directions: The first one is, when the domain name registrant has bad behavior "encroaching" or violating the rights of the owner of the protected mark (this is a common and traditional conflict, arising right from the emergence of the internet). The second is when the owner of a protected trademark abuses their monopoly and tries to obstruct the other actors from registering and using domain names in good faith, reverse hijacking the domain name. The mission of the law is to draw the boundary of the rights of the two actors so that one's rights do not encroach on each other. Thus, the question is the rights of which actor will be protected in the cases of conflict and whichprinciples and methods should be applied to resolve this conflict?

Trademarks have absolute territorial protection and legal monopoly, especially the right to prevent others from using it, therefore cannot be "assimilated" with an international object such as domain names. Before studying methods to resolve the conflict between the protection of IPR for trademarks and domain names in the stage of establishing rights, it is necessary to outline the principles of application. As mentioned above, there are two general principles applied to resolve conflicts and overlapping in the protection of IPR objects, that is: the principle of "first possession" (first in time, first in right) and the principle of protecting the party in good faith. In the stage of establishing rights, the author believes that the principle of first possession, or "first in time, first in right", should be applied to deliver an appropriate method of conflict resolution. As an ancient and decisive principle in resolving conflicts related to property [5], the principle of "first in time, first in right" is understood as "establishing rights first to be prioritized for protection first". Accordingly, the time of establishing rights for trademarks and domain names is the basis to determine which objects are prioritized for protection first. This is perhaps the best way to achieve fairness between two category of interests (trademark owners and domain name registrants), so that no party has precedence over the other, the trademark owner cannot take advantage of their monopoly to limit the rights of other actors if they have not established their rights in advance. However, if only person establishing their rights first is concerned, the law may not necessarily achieve the goal of absolute fairness because it has failed to consider cases when rights are established for the first registration but not in good faith. Therefore, based on the principle of first possession, conflicts can be prevented and resolved by the exchange of information mechanism between the two registration agencies. Information exchange is the connection of information between parties, so that both parties are aware of the existence of the other party. Only when the mechanism of information exchange is implemented and the principle of first possession is applied can justice be achieved and conflicts be controlled.

\subsection{Conflicts Between Protection of Industrial Property Rights for Trademarks and Domain Names in Terms of Content, Scope of Protection and Methods of Conflict Resolution}

The conflicts between the protection of IPR for trademarks and domain names in terms of content and scope of protection usually have the following common forms:

Firstly, a domain name holder registered a domain name but does not use it. In this case, the trademark owner are prevented from registeringthat the concerned domain name. Therefore, even though the domain name registrant does not use the registed domain name, there exists an overlap between the scopes of rights of the actors.

Secondly, the domain name registrant uses the domain name for products and services that are identical or similar to the trademark's products and services in order to mislead consumers. In the caseof this conflict, the method of resolving the conflict is to apply the law against unfair competition or different means of dispute resolution (including out-ofcourt and in-court remedies).

In addition, the precedents of European and American countries have recorded a number of other cases of conflict, notably the 
"Yellowstone Club" case [6]. The owner of the protected trademark "Yellowstone Club" of the United States has filed a complaint against a domain name registrant for having registered three domain names which are "yellowstoneclub.net" "'yellowstoneclubscandal .com", and "themellowstoneclub.org". However, according to the Court's decision, among the 3 domain names above, the domain name "yellowstoneclubscandal.com" was not revoked because the registration and use of this domain name is not for commercial purposes but to exercise the freedom of speech. For the remaining two domain names, the Court relied on the doctrine of initial interest confusion to revoke and restore those domain names for the trademark owner. Through the above case, we can see that the world has recorded a new type of conflict arising between the protection of IPR for trademarks and domain names, in which it is clearly defined whether the use and registration of domain names are for fair competition or not, and for commercial or noncommercial purposes.

Methods of resolving conflicts on the content and scope of protection

In the author's opinion, the two principles of "first in time, first in right" and the principle of protecting the party in good faith should be applied simultaneously to propose appropriate solutions for conflict resolution. In particular, if the principle of "first possession" is based on the time of rights establishment to determine which objects are prioritized for protect, the second principle supports the first principle to ensure fairness for the concerned parties.

A typical example demonstrating the application of the two principles mentioned above is the case related to the trademark GoPets of the United States. In 1999, Edward Hise registered the domain name GoPets which is associated with veterinary-related services and later internet-related services, domain name registration and maintenance services. During the development of the GoPets domain name, Hise registered more than 1300 domain names, mainly for websites to provide services in the future which are similar domain names such as "ehinges.com", “ebenches.com”, "erivets.com", "esconces.com". In 2004, Erik Bethke founded GoPets Ltd. in Korea and filed an application for the service trademark "GoPets" in the United States. Then, since 2004, Bethke has repeatedly tried to buy the GoPets domain name from Hise but failed. Since 2006, Hise has registered additional domain names such as "gopet.mobi", 'gopets.mobi", "gopets.name", "gopet.biz", "gopet.org", "egopets.com", "gopets.bz", "gopets.ws", "gopet.tv", "gopet.ws", "gopet.bz", "gopet.de", "gopet.eu" and "gopet.nam". In 2007, a few months after Hise offered to sell gopets.com for $\$ 5$ million, GoPets Ltd. filed a complaint against Hise at the California's Court. The lawsuit accuses Hise of trademark infringement and unfair competition under the Lanham Act and the law of California. Finally, the Court clearly defined that: i) the domain name GoPets was registered and had been used by Hise since 1999 (before Bethke's GoPets trademark was born) so it would continue to be used, ii) the domain names registered by Hise after the registration of the GoPets trademark shall be revoked.

In the first case, Hise's GoPets domain name registered and used since 1999 can continue to be used without revocation because Hise is the first one to establish rights and not the trademark registrant. And in the second case, Hise's other domain names were reregistered after the GoPets trademark was established, at that time the plaintiff's trademark had built up a wide reputation, so it was possible to prove the defendant's bad intent. Therefore, domain names registered after the trademark was established must be revoked. The two decisions of the Court clearly based on the two principles that ensure the fairness of property law which are the principle of first possession and the principle of protecting the party in good faith. These valuable precedents will be very important for the law of Vietnam to refer to in order to anticipate and prevent possible conflicts that may occur in the future because legal solutions in the field of ecommerce among countries are generally quite harmonious, unified and it is possible to learn 
from each other's experiences without too many barriers to legal integration. From the specific case of conflict above, the author realizes that the methods to resolve the conflict between the protection of IPR for trademarks and domain names in terms of content and scope of protection must be able to establish the boundaries to define acts of unfair competition or misappropriation of the domain name registered and used by the registrant, and define when there is an excessive abuse of power by the trademark owner. This means that there should be a method of conflict resolution by substantive law (law against unfair competition) and conflict resolution by procedural law (resolution by mediation, arbitration, or going to court).

\section{Current law of Vietnam on Conflict Resolution Between Protection of Industrial Property Rights for Trademarks and Domain Names}

\subsection{Conflicts Between Protection of Industrial Property Rights for Trademarks and Domain Names in Establishing Rights and Methods of Conflict Resolution in Accordance With Current Law of Vietnam}

Section 1.2 of Circular No. 01/2007/TTBKHCN on Guiding the Implementation of Decree No. 103/2006/ND-CP dated September 22, 2006 of the Government on Specifying and Guiding the Implementation of Certain Provisions of the Law on Intellectual Property states that: "Industrial property rights to a trademark are established on the basis of a decision of the National Office of Intellectual Property on granting a protection title." [7]. Circular No. 24/2015/TT-BTTTT on the Management and Use of Internet Resources clearly states that: "Agencies and organizations related to domain names specified in clause 1 of this Article have the responsibility to register and reserve domain names with the Ministry of Information and Communications (VNNIC)" [8]. Therefore, trademarks and domain names have the same function but are governed by two independent registration systems, so conflicts are inevitable.

As previously mentioned, there are three forms of conflict between the protection of IPR for trademarks and domain names in the stage of establishing rights: Registration of a domain name identical with a trademark (Cybersquatting), registration of a domain name confusingly similar to a trademark (Typosquatting) and reverse domain name hijacking (RDNH). Currently in Vietnam, there are mostly conflicts in the first two forms, that is, registration of a domain name identical with a trademark and registration of a domain name confusingly similar to a trademark, there are almost no cases of conflict of the third form (RDNH).

Clause 1, Article 130 of the Law on Intellectual Property defines "unfair competition" as: "Registration, seizure of the right to use or using a domain name identical or confusingly similar to a protected trademark or trade name belong to others or a geographical indication that they do not have the right to use for the purpose of misappropriating a domain name, taking advantage of or damaging the reputation of the corresponding trademark, trade name, or indication."

Therefore, it can be seen that the two most common forms of conflict in the stage of establishing rights mentioned in clause 1, Article 130 of the Law on Intellectual Property are "registration of a domain name identical with a protected trademark belong to others" and "registration of a domain name confusingly similar to a protected trademark belong to others". Clause 1, Article 4 of Joint Circular No. 14/2016/TTLT-BTTTT-BKHCN on Guiding the Procedures for Change and Withdrawal of Domain Names Violation the Law on Intellectual Property, the act of registering and using the domain name ".vn" is also mentioned: "The determination of registration and use of the domain name ".vn" violating the law on intellectual property and application of measures to force changing the 
domain name information, forced return of domain name, and revocation of the domain name ".vn" are carried out in accordance with the laws on intellectual property, information technology and telecommunications, following the conclusion or decision of a competent authority or person competent for applying sanctions for administrative violations in the field of intellectual property".

Although not mentioned in a unified instrument, through the provisions on unfair competition (Clause 1, Article 130 of the Law on Intellectual Property) and on measures to handle domain names violating the law on intellectual property (Circular No. 14/2016/TTLT-BTTTT-BKHCN), we find that the Vietnamese law has recognized a common form of conflict in the stage of right establishment, which is "domain name hijacking". "Domain name hijacking" happens when another's protected trademark is registered for a domain name for profit purposes. This form of conflict is not only common in Vietnam but also in many countries around the world, including the United States. As a leading country in promulgating laws to address the challenges related to domain names facing intellectual property rights in general and trademarks in particular, the United States has made great efforts in expanding and applying flexible provisions regulating trademarks in the internet environment, including the Anticybersquatting Consumer Protection Act (ACPA). The ACPA was created to prevent domain name hijacking, allowing trademark owners to sue domain name registrants who register domain names with bad intent.

+ Conflict resolution method: Although there are two forms of conflict between the protection of IPR for trademarks and domain names during the period of right establishment in Vietnam, the current law in Vietnam hasn't had any provisions on preventive conflict resolution, the current provisions only provide for administrative measures after the conflict has occurred. According to the conflict of rights theory, in order to ensure the principle of fairness and balance the interests of the parties during the stage of establishing rights, it is necessary to follow the principle of first possession, or "first in time, first in right", thereby applying the mechanism for information exchange between the two registration systems. It is necessary to have an information connection between the two parties so that the parties know the existence of each other, then based on the time of rights establishment of the two parties to decide which objects are prioritized for protection.

However, the allocation of domain names is now under the management of the Vietnam Internet Network Information Center (Ministry of Information and Communications), while the trademark registration procedure is under the management of the National Office of Intellectual Property (Ministry of Science and Technology). There is no instrument dedicating to specify the registration of trademarks containing domain names, and there are no separate provisions governing the allocation of domain names related to trademarks. The current provisions on establishing UPR regarding trademarks and domain name registration are still under two different agencies, with two different and unrelated procedures for rights establishment. This is a big "gap" of the current legal system on resolving conflicts between the protection of IPR for trademarks and domain names at the stage of establishing rights.

4.2. Conflicts Between the Protection of Industrial Property Rights for Trademarks and Domain Names in Terms of Content and Scope of Protection and Methods of Conflict Resolution in Accordance With Current Law of Vietnam

\subsubsection{Conflicts in the Protection Content}

In Section 2.2 of this paper, the author has identified two cases: the domain name registrant does not actually use the domain name and the case when they do use the registered domain name. The consequences of these two cases are different. In the first case, 
although the trademark owner is prevented from having the right to register the domain name, since the domain name registrants are not using it, there is no conflict. In the second case, a domain name registrant uses a domain name that is identical or confusingly similar to a trademark and has products and services that are identical or similar to the products and services of the trademark in order to mislead consumers. In Vietnam today, the second case (a domain name registrant uses a domain name with identical or similar products or services to the those of the trademark) is the most common conflict.

The law of Vietnam recognizes the rights of trademark owners, including the right to use, the right to prohibit others from using, and the right to dispose [9]. Domain name registrants, according to the law, have the right to use and the right to transfer the right to use the domain name [8]. Thus, these two objects share the same function (commercial indication) but are governed by different laws (law on intellectual property and law related to domain names), therefore conflicts of rights are bound to occur. Today, when the functions of trademarks are expanded, the rights of the trademark owner tend to go as far as to "encroach" on the rights of the domain name registrant. Especially in the age of e-commerce, not only the rights of trademark owners are expanded but also the rights of the domain name registrants. As a result, conflicts are more likely to occur. The development and the expansion of those two groups of interests has set out two fundamental objectives for the law, which are to protect the investment result of trademark owners, protect consumers and fair competitions, while ensuring internet freedom and e-commerce development.

4.2.2. Conflicts in the Scope of Protection

If the scope of IPR of trademarks are bounded within a nation, the scope of IPR of domain names are global. Article 93 of the Law on Intellectual Property affirms that "The IPR protection titles for objects of IPR in general and for trademarks in particular are effective within the territory of Vietnam". The IPR regarding trademarks are only effective within the territory of a nation, where the rights related to that trademark are established. In other words, only the national law of the country that accepted to protect that trademark may regulate the legal issues related to such trademark. Contrary to trademarks, domain names are globally unique. Each domain name can only be possessed by one entity regardless of the country or region where that domain name is registered.

Trademark protection depends on the existence of goods/services and are only granted the protection titles for specific goods/services, which is different from domain name protection. The domain name owners have the rights to make use of their domain names at their will. The domain name registrants are not restricted to use their domain names only for specific goods/services. Therefore, domain names can be used for both commercial and non-commercial purposes (education, information, entertainment) or any other purposes. However, it is not clearly specified whether the use of domain names for non-commercial purposes may lead to conflicts.

Methods of resolving conflicts in the content and scope of protection

On the theoretical basis of the conflict of rights between the protection of IPR for trademarks and domain names, and application of the principles of "first in time, first in right" as well as the principle of protecting the party in good faith, the law of Vietnam provides an appropriate method of conflict resolution to determine the boundary that defines acts of unfair competition or hijacking of domain names registered and used of another entity, and excessive abuse of power of the trademark owner.

First: Method of conflict resolution by provisions related to unfair competition

Under Article 130 of Law on Intellectual Property, the act of "seizure the right to use or using a domain name identical or confusingly similar to a protected trademark belong to others for the purpose of misappropriate a 
domain name, taking advantage of or damaging the reputation of a trademark" [9] is considered an act of unfair competition. However, there are still many issues that need to be clarified in the application of this law, which are: i) determination of "confusingly similar", ii) whether the purpose of the act of "seizure the right to use or using a domain name identical or confusingly similar to a protected trademark belong to others" "for the purpose of misappropriate a domain name" is appropriate or not, and whether the provision is feasible if the consequences of the act of "seizure the right to use or using a domain name identical or confusingly similar to a protected trademark belong to others" only stops at "damaging the reputation of a trademark", and iii) "bad intent" or "dishonesty" in "seizure the right to use or using a domain name".

Regarding the possibility of "confusing similarity": Determining a domain name of "confusing similarity" with a protected trademark is not simple because it depends on many criteria and the context of specific situations. According to Article 39.8 of Circular No. 01/2007/TT-BKHCN, in order to assess the confusing similarity of one trademark with another (for word marks), "it is necessary to compare the structure, content, pronunciation, form of expression" [7]. In fact, the above criteria are also used to assess the possibility of "confusing similarity" between trademarks and domain names. The problem is that domain names are not subject to IPR, therefore is it appropriate to apply the criteria for assessing the possibility of confusing similarity between objects of IPR for domain names? There are still many contrary points of view on this question.

Regarding the consequences of the act of "seizure the right to use or using a domain name identical or confusingly similar to a protected trademark or trade name belong to others", according to competition law in general, the consequences of this act are "damaging or posing a risk of damage to the interests of enterprises and consumers", while according to
Article 130 of the Law on Intellectual Property, the consequence is "damaging the reputation of the trademark". Compared with the consequences specified in the competition law, the consequences of unfair competition according to the law on intellectual property are more restricted in scope [10]. In fact, providing the consequences under the provision "damaging the reputation of the trademark" creates difficulties in application and is somewhat inappropriate since the important issue here is identifying the victim of those consequences, whether they are consumers or businesses. Moreover, the purpose of the act of "seizure the right to use or using a domain name identical or confusingly similar to a protected trademark or trade name belong to others" is not simply "for the purpose of misappropriating a domain name". If only addressing the consequences and purposes of such behavior, it may be insufficient to conclude whether it is an act of unfair competition or not.

Regarding "bad intent", this is an issue that has not yet been mentioned in Article 130 of the Law on Intellectual Property. The ACPA of the United States defines "Domain name cybersquatting" as "a person taking another's protected trademark to register as a domain name for the purpose of reselling it to the trademark owner for profit purposes." This Act allows a trademark owner to sue a domain name registrant in case they register the domain name with bad intent and register, sell, and use a domain name under one of the following three circumstances: [11]

+ There is an identical or confusing similarity to a protected trademark

+ There is an identical or confusing similarity to well-known trademarks or obstruction to well-known trademarks

+ The trademark is related to certain distinctive signs such as the Red Cross or the Olympic Games emblem.

As such, the ACPA clearly sets forth the legal basis for trademark owners in the United States to sue domain name registrants. In particular, the factors for determining a 
registration with "bad intent" are specified very clearly, making it is easier for trademark owners to use as a basis for suing.

Second: Methods of conflict resolution by other judicial institutions

In Vietnam, domain name disputes have appeared since the early 2000s, however, for a long time, Vietnam has not had any policy on resolving domain name disputes, therefore disputes have not been thoroughly resolved. The main solution recommended by the Vietnam Internet Network Information Center ("VNNIC") under the Ministry of Information and Communications, the agency in charge of allocation and administration of national domain names in Vietnam, is negotiation and reconciliation among disputing parties themselves.

However, domain name disputes are a special type of dispute, so it is still necessary to issue a specific legal mechanism to serve as a legal basis for the parties to settle disputes by going to court or through arbitration. Therefore, after conducting research into the practice of resolving domain name disputes worldwide, the Ministry of Information and Communications and the Ministry of Science and Technology issued Circular 14/2016/BTTTT-BKHCN dated June 8, 2016 on Guiding the Procedure for Changing and Revoking Domain Names Violating the Law on Intellectual Property. Accordingly, clause 2, Article 4 of the Circular affirms: "Measures to force changing the domain name information, force return of domain name, and revoke domain names with ".vn" violating the law on intellectual property shall be considered to be applied in the following cases:

i) The domain name is identical or confusingly similar to the protected object of intellectual property right and the content posted on the website accompanying the domain name violates the law on intellectual property. ii) The domain name is used to post information that violates the law on intellectual property."

In addition, Circular No. 24/2015/TTBTTTT dated August 18, 2015 also contains provisions related to the management and use of internet resources. According to the current provisions, the disputing parties can choose one of the three methods of dispute resolution: conciliation, arbitration or lawsuit in court.

Article 16 of Decree No.72/2013/ND-CP on Management, Provision and Use of Internet Services and Electronic Information on the Internet reaffirms the above-mentioned forms of domain name dispute resolution, and provides specific provisions on the grounds for dispute settlement at the request of the plaintiff: (a) The disputed domain name is identical or confusingly similar to the name of the plaintiff; identical or confusingly similar to a trademark or service mark over which the plaintiff has legitimate rights or interests; (b) The respondent has no legitimate rights or interests in relation to that domain name; (c) The defendant leases or transfers the domain name to the plaintiff who is the owner of the name, trademark or service mark identical or confusingly similar to that domain name; leases or transfers the domain name to a competitor of the plaintiff for personal interests or for illicit gain; (d) The defendant uses the domain name to damage the reputation of the plaintiff, obstruct the plaintiff's business, or cause confusion or loss of public trust in the name, trademark, service mark of the plaintiff for the purpose of unfair competition; (e) Other cases with proves that the defendant's use of the domain name violates the legitimate interests of the plaintiff. In addition, Article 16 of Decree No. 72/2013/ND-CP also provides cases where the defendant is considered to have legitimate rights and interests related to the domain name if one of the following conditions is met: (a) The defendant has used or has clear evidence of preparing to use the domain name or the name corresponding to that domain name in connection with the actual supply of products, goods or services prior to the dispute; (b) The 
defendant is known to the public by that domain name even though they has no rights to a trade name, trademark, or service mark; (c) The defendant is using the domain name in a lawful manner not related to commerce, or using the domain name in a legitimate manner not for commercial purposes or for the purpose of misleading or confusing the public, affecting the name, trade name, trademark, and service mark of the plaintiff; (d) There is other evidence proving the legitimacy of the defendant in relation to the domain name. The Decree also sets out the principle of handling disputed domain names of the agency managing the domain name ".vn" in accordance with the minutes of successful mediation between the disputing parties or according to a legally effective decision of the arbitration agency or according to a legally effective judgment or decision of the Court.

\section{Solutions to Improve the Law of Vietnam on Resolution of Conflicts Between Protection of Industrial Property Rights for Trademarks and Domain Names}

On the basis of the theoretical grounds presented in sections 1 and 2 above and the analysis of the current law of Vietnam regulating conflicts and conflict resolution between the protection of IPR for brands and domain names, the author proposes two groups of solutions:

\subsection{Group of Solutions to Resolve Conflicts} Between Protection of Industrial Property Rights for Trademarks and Domain Names in the Stage of Right Establishment

5.1.1. Developing Provisions on Information Exchange During the Examination of Trademark Applications as Well as the Domain Name Registration Process

Based on the theory of the principle of first possession, or "first in time, first in right", this paper aims to establish provisions on conflict prevention with the information exchange mechanism between two registration systems.
This solution is to harmonize and balance the two different groups of interests. Establishing rights is the first stage of the whole protection process. The majority of conflicts in this stage are two objects having the same function (industrial indication) but are governed by two different registration systems.

Worldwide, ICANN has raised the issue of protecting the rights of registrants when applying the "Trademark Clearinghouse TMCH" mechanism to resolve issues related to trademarks. This mechanism provides two services: trademark claims service and early registration service (Sunrise service). Accordingly, when it is confirmed that a trademark is to be registered under the TMCH mechanism, "Trademark Claims Service" will assure the registrant that whenever someone registers the domain name (under the new toplevel system) which coincides with the trademark already registered in the $\mathrm{TMCH}$, the registrant of that domain will be notified that a similar mark already exists. If the domain name registrant continues to register and is granted a domain name, TMCH will send an email notification to the trademark owner knowing that the domain name associated with the trademark has been registered. Thus, it can be said that ICANN's "trademark claim service" may not completely prevent trademark infringement because domain name registrants can still choose to continue and potentially infringe domain name registration. However, this process will make it easier to identify the "bad intent" of the domain name registrant. Basically, it is considered an effective measure to prevent the acts of "misappropriating domain names".

In Vietnam, trademarks are subject to regulation by the Law on Intellectual Property, managed by the Ministry of Science and Technology, while domain names are governed and managed by the Ministry of Information and Communications. Currently, the databases for the registration process of these two agencies are not connected to each other. During the examination of a trademark application, the officers of the National Office 
of Intellectual Property of Vietnam (NOIP) evaluate and decide on the protectionability of the trademark on an absolute basis (Article 73 of the Law on Intellectual Property) and a related basis (Article 74 of the Law on Intellectual Property) and cross reference from the NOIP's database system. Domain names are not regulated by Law on Intellectual Property and the NOIP's database system for cross reference of trademarks does not include data related to domain names that have been filed at VNNIC. Considering the situation in Vietnam and the ICANN's TMCH mechanism, the author believes that the solution for conflicts prevention in the right establishment stage should begin from the information exchange mechanism. To concretize this mechanism, the following two solutions can be studied:

First: Cross-check in the examination process. The NOIP must share data on trademarks that have been protected or registered with VINNIC. And vice versa, VNNIC as a domain name data management agency also provides data on domain names to NOIP. And the trademark examiners at the NOIP as well as the person in charge of appraising the domain name registration file during the appraisal process will have the duty to cross-check the other object. If this solution can be implemented, it will help to avoid granting protection to trademarks that are identical or similar to a domain name, or allowing the registration of a domain name that is identical or similar to a trademark. Howeverwe have to face the risk of infeasibility of sharing data between two agencies, since data security issues are involved, the procedure and implementing process will likely to be costly and time-consuming.

Second: Giving recommendations to registrants of trademarks and domain names to actively pursue cross-check procedures at the NOIP and VINNIC before submitting the application file so as to timely assess whether there are pre-existing trademarks or domain names. This is considered a more feasible solution to prevent conflicts from occurring.
5.1.2. Expanding the scope of the provision on assessment of trademarks distinctiveness in Article 74.2 of the Intellectual Property Law

International economic integration and the strong development of e-commerce requires constant improvement and adaptation of the legal system. As part of the legal system, amending the IP Law to suit the current context is inevitable. The protection of intellectual property rights is carried out throughout the process from establishing rights, exploiting rights and protecting rights. In particular, establishment of rights is the first stage of the whole protection process, so if it is operated smoothly, if the governing provisions for this stage are effective and unified, later conflicts and disputes will be minimized.

The revised Law on Intellectual Property in 2009 provides a list of cases in which a trademark is considered indistinguishable with 13 clauses in Article 74.2. Other than the provisions related to the refusal of a trademark because due to similarity to objects such as trade names, geographical indications, and industrial designs, there are no provisions governing the refusal of a trademark due to similarity to a domain name since domain names are not yet a subject of intellectual property rights, and therefore, the examiners of the NOIP during the examination of trademark application files have no basis to evaluate the protection ability in case of similarity between trademarks and domain names. Therefore, one of the solutions that may be taken into account by legislators to improve the law on intellectual property is to add a clause in Article 74.2 which provides for "Marks identical or similar to domain names that are being used by others, if the use of such marks may cause confusion to consumers about the origin of the goods or services". Only when the relationship between the protection of IPR for trademarks and domain names is regulated even from the stage of rights establishment can the conflicts between the protection of industrial property rights for trademarks and domain names be prevented, avoiding conflicts at later stages of the protection process. 
5.1.2. Amending the Regulation on Examination of Trademark Applications

Despite of being an direct preventive solution, this is an important solution that should be implemented early in the process of resolving and preventing conflicts between IPR protection for trademarks and domain names because after 10 years of application, Vietnam's regulation on trademark examination is no longer keeping up with the changes in the law as well as the strong development of the Internet and e-commerce. Vietnam should learn from the experiences of the United States and the European Union Intellectual Property Office when developing the Regulation on Examination of Trademark Applications, specifically adding to the current Regulation on Examination of Trademark Applications specific instructions for cases of registered trademarks with a domain name; so that examiners have the basis to quickly and consistently make conclusions.

5.2. Group of Solutions to Resolve Conflicts Between Industrial Property Rights Protection for Trademarks and Domain Names in Terms of Content and Scope of Protection

5.2.1. Amending Point d, Clause 1, Article 130 of the Law on Intellectual Property on Unfair Competition Practices

What is correct understanding of unfair competition practices related to domain names specified at point d, clause 1, Article 130 of the Intellectual Property Law? According to this provision, a registers, seizes the right to use or uses a domain name that is identical or confusingly similar to a trademark that it does not have the right to use for the purpose of appropriating its name domain, taking advantage of or damaging the reputation and reputation of the mark is considered an act of unfair competition.

Domain name registration is the implementation of the procedure for that domain name to be recognized, activated and exist on the Internet. (Section 2.6 Circular No. 09/2008/TT-BTTTT Guidance on management and use of Internet resources). According to the principle of domain name registration mentioned above, whoever registers first will be allocated first, therefore any subject can register any domain name as long as it does not overlap with other domain names. However, it is a fact that there are numerous types of domain names such as international domain names (.com, .net,...), national domain names (.vn; .uk,...), second and third level domain names (.com.vn), so sometimes a business entity may only registers one domain name and other entities will take advantage of this loophole to register other similar domain names.

Cybersquatting occurs when someone registers a domain name before the trademark owner can register it, but may not use it and merely intends to prevent the trademark owner from registering the domain name.. This act often comes from competitors to chanllenge trademark owners. Another purpose is to resell the domain names to trademark owners. However, it is also possible that the registrant put the domain name into use for different purposes. "Using a domain name is attaching that domain name to the Internet address (IP address) of an active server for online applications; or to protect trademarks, trade names, service names, organization names from being misappropriated (Section 2.7 of Circular No. 09/2008/TT-BTTTT).

However, the problem here is that a domain name can be identical or similar to many trademarks (registered for products/services that are not identical or similar). So which of the above trademarks is the trademark being infringed? The law of Vietnam should clearly stipulate that the infringing domain name is one that is identical or similar to a protected trademark of another subject and registered for products/services that are identical or similar to those of another subject or even if not identical/similar in terms of products/services, that mark has been widely used in Vietnam. If the registration, seizure of the right to use, the use of these domain names are not identical or similar and do not cause confusion to consumers between that domain name and another protected trademark, trade name, or geographical indication, it is not considered an 
act of unfair competition. Because a domain name is only valid when it is associated with a trademark, a reputable trade name or a geographical indication - the objects of IP rights, those are objects that are aimed at for profit purposes. The determination of the similarity between domain names and trademarks, trade names or geographical indications is not specified, but can basically be evaluated according to the process of assessing infringements of rights related to trademarks, trade names and geographical indications. However, there is one feature, domain names are only expressed in the form of alphanumeric characters, so they can only be confused with trademarks and geographical indications expressed in characters only. If such geographical indication or mark is presented in the form of images or colors, it will not cause confusion.

Furthermore, it should only be handled when the domain name owner uses that domain name to give false information about another trademark owner's products/services. In case the domain name owner registers the domain name for other purposes, it should not be considered as an act of unfair competition. Therefore, using the domain name for the right purpose, without affecting the reputation and of the trademark owner, should be of great concern to businesses.

Article 18.28 of the CPTPP requires appropriate sanctions to deal with cases where a person registers or holds a domain name that is identical or confusingly similar to a trademark in order to gain illicit profits, while Article 130 of the Law on Intellectual Property stipulates that just the act of registering for the purpose of occupying a domain name identical or confusingly similar to a trademark is considered an act of unfair competition and this domain name can be revoked under the provisions of the Decree No. 99/2013/ND-CP. Joint Circular No. 14/2016/TTLT-BTTTT-BKHCN guiding the order and procedures for changing and revoking domain names in violation of the law on intellectual property also stipulates that domain name revocation measures are only applicable when "The domain name is identical or confusingly similar to the intellectual property object being protected and the content posted on the website accompanying the domain name violates the IP law". In addition, the provisions of the Law on Information Technology and the Law on Telecommunications do not prevent the registration and reservation of domain names under the first-come-first-serve mechanism. Thus, compared with Article 18.28 of the CPTPP, the provision at point $\mathrm{d}$, clause 1 , Article 130 are somewhat stricter than the requirements of international treaties.

Therefore, in order to ensure that the sanctions for domain name revocation are consistent with other laws, in line with the general trend of the world, it is necessary to amend the provisions on unfair competition related to domain names in the IP Law according to the provisions of the Law on Intellectual Property. The only direction is when this act of appropriation is "for malicious purposes", namely to profit, to take advantage of the name of a well-known brand, to prevent foreign enterprises' access to the market, etc., does it constitute acts of unfair competition and thereby leads to the sanction of domain name revocation. Therefore, in the author's opinion, point d, Clause 1, Article 130 should be revised in the direction that the act considered as an act of unfair competition is the act of "Registration, seizure of the right to use or use domain names that are identical or confusingly similar to another's trademarks, protected trade names or geographical indications that you do not have the right to use for the purpose of possessing the domain name with malicious intent, taking advantage or occupying the right to use or use a domain name that is identical or confusingly similar to a trademark, causing damage to the reputation and reputation of the respective mark, trade name or geographical indication".

5.2.2. Developing Policy on Uniform Dispute Resolution Related to Domain Names in Vietnam 
On October 24, 1999, the ICANN Council officially approved the UDRP and issued the "Unified Domain Name Dispute Resolution Charter" (UDRP Charter) to specifically guide UDRP. Dispute resolution under UDRP is a very effective solution to protect trademarks against domain name misappropriation. However, this model still has some disadvantages.

In Article 18.28 of the Intellectual Property Chapter, the CPTPP requires Vietnam to come up with a mechanism for resolving domain name disputes in accordance with the Uniform Domain Name Dispute Resolution Policy (UDRP) procedure, specifically: an appropriate dispute resolution procedure, based on, or modeled on, the guidelines and principles set forth in the Uniform Domain Name Dispute Resolution Policy, which is assigned a number and name by the Organization on Internet (ICANN) adopted". Accordingly, the policy must ensure (i) is designed for immediate and low-cost dispute resolution; (ii) fair and reasonable; (iii) not unduly burdensome; and (iv) does not exclude court proceedings; and (b) online public access to an accurate and reliable database of contact information relating to domain name registrants; in accordance with the laws of each Party and, where appropriate, appropriate administrative policies regarding the protection of privacy and personal data". In addition, the Agreement also affirms that "appropriate sanctions should be in place at least in the event that a person registers or holds a domain name identical or confusingly similar to a trademark for the purpose of not healthy for profit".

The author proposes to build a specific model for the policy on dispute resolution related to domain names for Vietnam, on the basis of the general requirements set forth in the CPTPP Agreement, on the basis of reference to the advantages of the Government. Unified Domain Name Dispute Resolution Manual of UDRP and modified to suit the circumstances of Vietnam. In addition, this model has additional references to some provisions of the US Consumer Protection
Against Domain Name Misappropriation Act (ACPA). In particular:

First: The complaining party (trademark owner), to prove that its rights have been violated, must prove three factors:

+ The domain name is identical or similar to a trademark or service mark to which the Complainant is entitled;

+ The complained person has no legitimate rights or interests in the domain name;

+ The domain name has been registered and is being used for malicious purposes.

The above factors are called "3-step test" to prove domain name misappropriation. Specifically:

i) Determine what is identical or confusingly similar trademark and domain name. In this case the concerned trademarks shall be compared to the 2nd level domain name.

ii) Determine how the complainant "have no legitimate rights and interests to the domain name".

iii) Define what is considered as "bad faith" for both domain name registration and use.

Second: The new policy will clearly define the scope of application which ist to resolve disputes related to conflicts between the domain name ".vn" and trademarks protected by he Vietnamese law.

Third: The policy is applied to disputed domain names managed by VNNIC.

Fourth: Provide a specific dispute resolution period, possibly two years, for applicable domain name disputes, except where disputes involving well-known trademarks may have a different time limit.

Fifth: The dispute settlement agency is an organization recognized and authorized by VNNIC.

Sixth: The complainant must be the trademark owner and the complained party is the registrant or user of the domain name.

To apply this model, VINNIC will have to authorize an Arbitration Center or there will be an organization with a dispute resolution function. After receiving the complaint, the Center/organization will set up an Expert Panel to deal with the complaint. Remedies include cancellation of the registered domain name or transfer of the registered domain name to the complainant. The aforementioned 
center/organization will set up a dedicated website, receive complaints related to domain name disputes online and publicly publish all information related to domain name dispute cases. A time limit similar to that of the UDRP may apply where within 14 days from the date of receipt of the complaint, the Panel of Experts will have to make a decision to resolve the case.

Although the unified domain name dispute resolution model is not new in the world, it is a model that has never been applied in Vietnam. Some countries such as China, the United States, the European Union, and Taiwan have been applying this model because of the its advantages.

\section{References}

[1] Gustavo Arosemena, Conflicts of Rights in International Human Rights: A Meta-rule Analysis, Global Constitutionalism, 2013.

http://journals.cambridge.org/abstract_S20453817 2000214

[2] Celia Lerman, Domain Name Dispute Resolution and the WTO Agreement on Trade Related Intellectual Property Rights,

https://www.wto.org/english/tratop_e/trips_e/colloq uium_papers_e/2012/chapter_1_2012_e.pdf.

[3] N. T. Q. Anh, Definition, Characteristics and Classification of Industrial Indications, Vietnam National University, Hanoi Science Project no. QG.11.45 "Improving the Law of Vietnam on Protection of Industrial Indications in the International Integration Context".
[4] V. T. Thuy, Signs for Distinction in the Law on Trademarks - A Solution for Conflicts of Rights to Protection, Democracy and Law Journal, Ministry of Justice, 2011.

[5] Lawrence Berger, An Analysis of the Doctrine of "First in time, First in right", Nebraska Law Review, 1985.

[6] Daniel Greenberg, Initial Interest Confusion Plus noncommercial Freedom of Speech: Right or Legitimate Interest in an Infringing Domain Name?, Yellowstone Mountain Club LLC v Offshore Limited D and PCI Three Member Panel at the WIPO Arbitration and Meditation Center, Journal of Intellectual Property Law \& Practice, 2013.

[7] Ministry of Science and Technology (2008), Circular No. 01/2007/TT-BKHCN dated February 14, 2007 Guiding the Implementation of Decree No. 103/2006/ND-CP dated September 22, 2006 of the Government on Specifying and Guiding the Implementation of Certain Provisions of the Law on Intellectual Property, Amended and supplemented according to Circular No. 13/2010/TT-BKHCN July 30, 2010, Circular No. 18/2011/TT-BKHCN dated July 22, 2011, and Circular No. 05/2013/TT-BKHCN Dated February 20, 2013, Hanoi.

[8] Ministry of Information and Communications, Circular No. 24/2015/TT-BTTTT Dated August 18, 2015 on the Management and Use of Internet Resources.

[9] The National Assembly of the Socialist Republic of Vietnam, Law on Intellectual Property, Hanoi, 2005

[10] N. P. Thao, Current law on unfair competition in the field of industrial property in Vietnam, Doctoral thesis, School of Law - Vietnam National University, Hanoi, 2018.

[11] [US Code, The Anticybersquatting Consumer Protection Act, (d) (1) (A), 1999. 